\title{
Two Modes of Product Development: Head-Oriented vs. Release-Oriented
}

\author{
Masayuki Hatta \\ Surugadai University, \\ Faculty of Economics, \\ 698, Azu, Hannou, Saitama, Japan \\ hatta.masayuki@surugadai.ac.jp \\ http: //about.me/mhatta
}

\begin{abstract}
In this paper, the concept of two different modes for product development process is proposed. One is "release-oriented" product development, which is a fairly common way to develop various products up to now. The other is "head-oriented" product development, which is recently observed especially in the field of software/content development. The distinguishing difference and possible merits and demerits of two modes are scrutinized.
\end{abstract}

\section{Introduction}

In the manufacturing industry, the product development is typically performed in aiming at the market release of a product. That is, trial experimentations are repeated inside the company, and a prototype is created when the concept and key features are stabilized to some extent (or scheduled deadline is imminent). After the so-called Quality Assurance work and some fine tuning are done, a final product is released to the market. This is mostly the same in the software industry until recently (Brooks 1975, Krishnan 1994).

However, recently, a different mode of product development has emerged, especially in the area of Open Source software/contents development and the development of on-line services such as SaaS (Software as a Service). In this mode, the target of development (typically the source code or running service) is always open to the public, and the insider developers and mere users share the same "forefront of development", or often called as "HEAD" in the developers' circle (Fogel \& Bar 2003).

\section{Release vs. Head}

In this paper, the former, more conventional type of the product development process will be called "Release-oriented". The release-oriented product development process has an independent Quality Assurance (QA) process and a discrete release (Fig.1). 


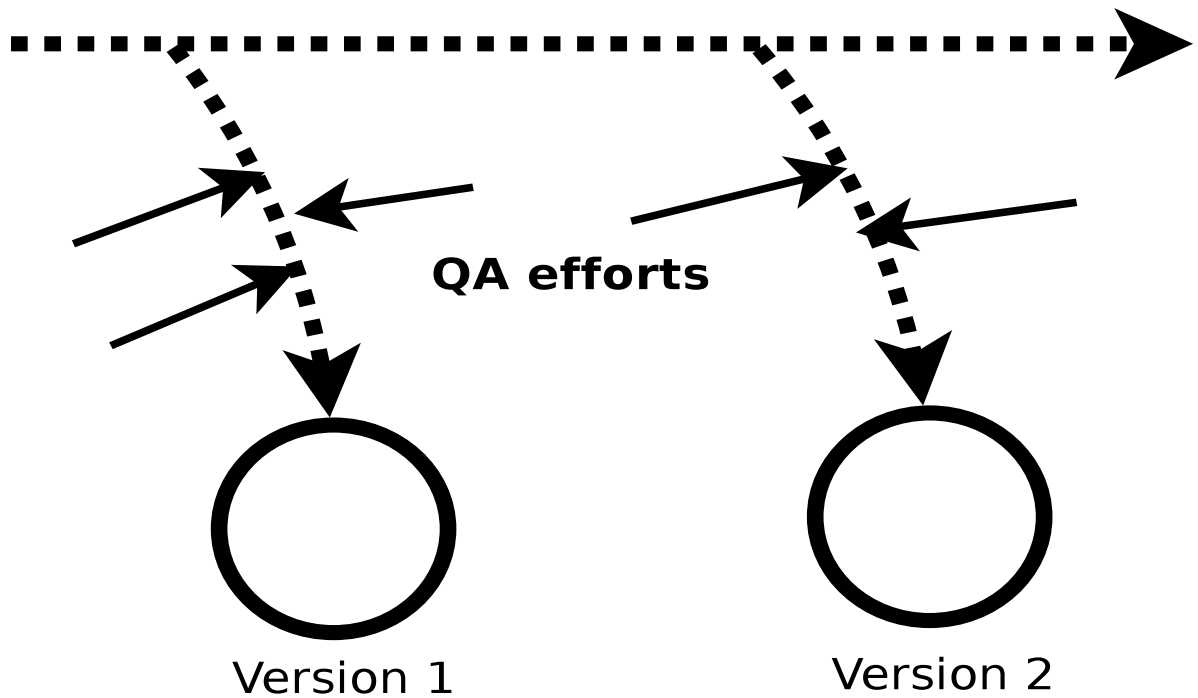

Fig. 1. The Release-oriented mode of product development. The dotted arrow indicates nondisclosed development. The solid circle means an officially released version of product.

By contrast, the latter one will be called "Head-oriented". The head-oriented way has no QA, no official releases, but the HEAD is open to the public (Fig.2).

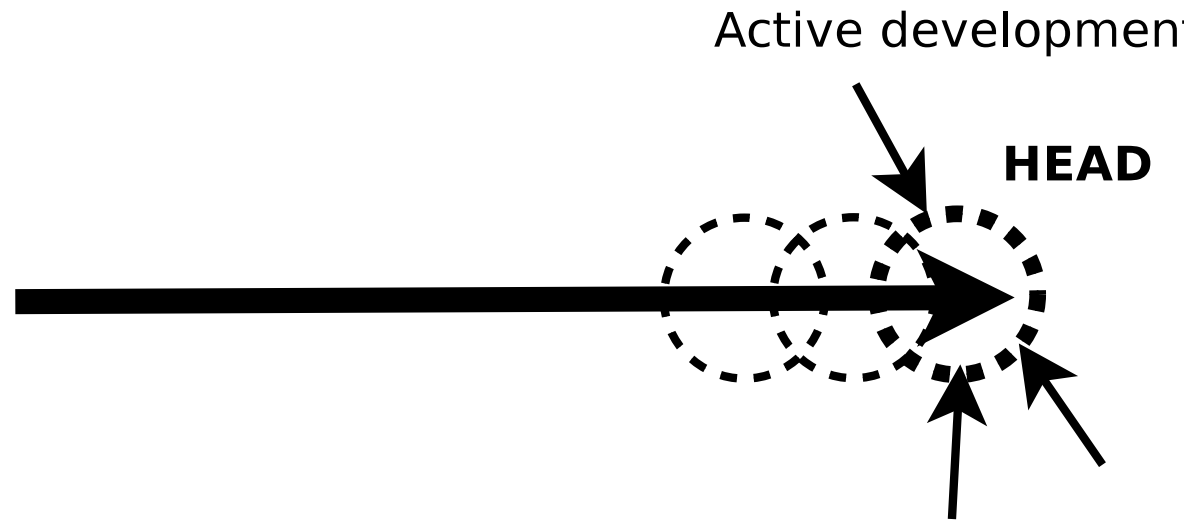

Fig. 2. The Head-oriented mode of product development. The head never released officially (except "snapshots"), thus indicated in the dotted circle.

The current development (writing/editing) process of Wikipedia is an excellent example of Head-oriented mode of product development. There are no "official releases". Instead, what you can see is always the latest edition. 


\section{The Key Elements Which Enabled the Head-Oriented Mode}

The head-oriented mode enables the project to grow fast and mostly developerfriendly, however it is highly probable that imperfect and unstable products will be delivered to the users if the head-oriented mode has taken place. In order to realize the head-oriented product development, some external conditions should be ready. In this research, the author emphasizes the importance of technical progress in the realm of development infrastructure, and especially, the attribution of users.

Finally, the author will investigate the recent confusion at the scene of the KDE Desktop 4.0 release. Some Open Source projects have faced strong and sudden criticism from users when they put the new release out. This can be explained by the difference of orientation toward product development and releases, between core developers and users.

\section{References}

1. Brooks, F.P.: The Mythical Man-Month: Essays on Software Engineering. Addison-Wesley, New York (1975)

2. Krishnan, M.S.: Software release management: a business perspective. In: CASCON 1994: Proceedings of the 1994 Conference of the Centre for Advanced Studies on Collaborative Research, vol. 36 (1994)

3. Fogel, K., Bar, M.: Open Source Development with CVS, 3rd edn. Paraglyph Press, New York (2003)

4. Von Hippel, E.: Democratizing Innovation. MIT Press, Boston (2005) 